DOI: $10.14451 / 1.169 .98$

\title{
ОСОБЕННОСТИ ПРИМЕНЕНИЯ МЕХАНИЗМОВ БЮДЖЕТНЫХ ИНВЕСТИЦИЙ И ИНИЦИАТИВНОГО БЮДЖЕТИРОВАНИЯ В КАЧЕСТВЕ ФИНАНСОВЫХ ИНСТРУМЕНТОВ РАЗВИТИЯ ТЕРРИТОРИЙ
}

\author{
(c) 2018 Сорокина Марина Сергеевна \\ кандидат экономических наук \\ Администрация города Курска \\ 305000, г. Курск, ул. Ленина, 1
(c) 2018 Белостоцкий Алексей Александрович
кандидат экономических наук, доцент
Курский государственный университет
305000, Курск, ул. Радищева, д. 33
E-mail: a.a.belostotskiy@yandex.ru

Исследование раскрывает отличительные особенности применения механизмов инициативного бюджетирования и бюджетных инвестиций, как основных финансовых инструментов, влияющих на обеспечение денежными ресурсами территорий, социально-экономическое развитие субъектов РФ и, в целом, выявлению положительных экономических эффектов, что, в конечном итоге позволит эффективно расходовать бюджетные ресурсы.

Ключевые слова: бюджетные инвестиции, инициативное бюджетирование, финансовые инструменты, развитие территорий, софинансирование проектов.

В современных российских условиях участие федерального и региональных бюджетов в финансировании инвестиций в реальный сектор экономики осложнено ограниченностью ресурсной базы бюджетной системы в связи с необходимостью финансирования повышенных социальных обязательств бюджетов. Без бюджетной поддержки из федерального центра изменить снижающуюся динамику инвестиций в российской экономике представляется чрезвычайно сложным, учитывая, что сегодня доля федерального бюджета в общих источниках финансирования колеблется на уровне 10\% [3].

Государственный бюджет играет определяющую роль в реализации социально-экономиче- ской политики, проводимой Правительством РФ и способствует эффективному решению социально-экономических задач [1, с. 135].

Правовые и экономические условия инвестиционной деятельности на территории Курской области регулируются законодательством Российской Федерации, Законом Курской области от 12.08.2004 г. № 37-3КО «Об инвестиционной деятельности в Курской области», другими законами и нормативными правовыми актами Курской области.

Сведения о бюджетных ассигнованиях по непрограммным направлениям деятельности приведены в табл.1.

Законом Курской области от 12.08.2004 г.

Таблица 1. Бюджетные инвестиции в объекты государственной собственности, тыс. рублей

\begin{tabular}{|c|c|c|c|c|c|c|c|c|c|}
\hline \multirow[b]{2}{*}{$\begin{array}{c}\text { Наимено } \\
\text { вание }\end{array}$} & \multirow[b]{2}{*}{$\begin{array}{c}2018 \text { г. } \\
\text { № 36- } \\
\text { 3КО от } \\
20.07 .2018\end{array}$} & \multicolumn{3}{|c|}{2019 год } & \multicolumn{3}{|c|}{2020 год } & \multicolumn{2}{|c|}{2021 год } \\
\hline & & \begin{tabular}{|c|} 
№ $36-$ \\
3КО от \\
20.07 .2018
\end{tabular} & Проект & $\begin{array}{c}\Delta \text { к зако- } \\
\text { ну,\% }\end{array}$ & $\begin{array}{c}\text { № 36- } \\
\text { 3КО от } \\
20.07 .2018\end{array}$ & Проект & $\begin{array}{c}\Delta \text { к зако- } \\
\text { ну,\% }\end{array}$ & Проект & \begin{tabular}{|c|}
$\Delta$ к зако- \\
нопроекту \\
на 2020 \\
год,\% \\
\end{tabular} \\
\hline 1 & 2 & 3 & 4 & $5=4 / 3 * 100$ & 6 & 7 & $8=7 / 6 * 100$ & 9 & $10=9 / 7 * 100$ \\
\hline $\begin{array}{l}\text { Бюджет- } \\
\text { ные инве- } \\
\text { стиции в } \\
\text { объекты } \\
\text { государ- } \\
\text { ственной } \\
\text { собствен- } \\
\text { ности }\end{array}$ & 4439,0 & 4500,0 & 4500,0 & 100,0 & 4500,0 & 4500,0 & 100,0 & 4500,0 & 100,0 \\
\hline
\end{tabular}


№ 37-3КО «Об инвестиционной деятельности в Курской области» предусмотрены следующие формы государственной поддержки инвесторов.

Инвесторам, реализующим инвестиционные проекты на территории Курской области, по одному и тому же инвестиционному проекту предоставляется только одна форма государственной поддержки, за исключением инвесторов, реализующих инвестиционные проекты, направленные на достижение целей и задач государственной программы Курской области «Развитие сельского хозяйства и регулирование рынков сельскохозяйственной продукции, сырья и продовольствия в Курской области», приоритетные инвестиционные проекты с объемом инвестиций в основной капитал более 2 млрд. рублей, инвестиционные проекты, направленные на выпуск инновационной продукции, а также инвестиционные проекты на территории индустриальных (промышленных) парков [5].

Наряду с общими подходами по формированию проекта областного бюджета, на изменение расходов по разделу повлияло уточнение средств областного бюджета на бюджетные инвестиции в объекты государственной собственности Курской области согласно принятым в установленном порядке Администрацией Курской области решениям о направлении бюджетных инвестиций, за счет увеличения в 2019 году на сумму 45593,4 тыс. рублей, увеличения в 2020 году на сумму 126945,3 тыс. рублей, уменьшения в 2021 году на сумму 102 645,3 тыс. рублей [4].

В отличие от реализации обычных инвестиционных проектов, например, строительства дороги, парка, дома культуры, в ходе реализации проектов инициативного бюджетирования появляются дополнительные эффекты, важнейшие из которых следует выделить:

1. Определение и решение наиболее острых социальных проблем поселений. Если наладить диалог с жителями, можно нащупать те вопросы, которые не всегда очевидны для чиновников, но решение которых оказывается критически важным для сообщества.

2. Минимизируется коррупция за счет максимальной прозрачности проекта и подлинного общественного контроля за ходом реализации проектов. Поскольку выбор приоритетов и реализация проекта проходят при непосредственном участии жителей, украсть деньги в рамках ИБ сложно. На всех этапах, от составления сметы до приемки работ от подрядчика, граждане ак- тивно вовлечены в проект и осуществляют общественный контроль.

3. Формируется социальный капитал поселений. Гражданские активисты и население вырабатывают навыки и компетенции, необходимые для представления общественных интересов. Одним из таких навыков, в частности, является умение вести публичную дискуссию и открыто обсуждать проблемы местного сообщества для получения общественного блага.

4. Активизируется совместная деятельность власти, бизнеса и населения, формируется общая вовлеченность и ответственность, которые подразумевают софинансирование со стороны населения и бизнеса. Внесение даже минимальных сумм на реализацию проекта включает хозяйское отношение к делам сообщества, повышает вовлечение граждан в процесс реализации проектов.

5. Стимулируется самоорганизация граждан и минимизируются иждивенческие настроения. Участвуя в делах поселений, граждане видят практический результат своих действий, начинают веритьв возможность изменить жизнь вокруг себя.

6. Повышается доверие населения к деятельности власти через конструктивный диалог между населением и муниципалитетами. Данный эффект является следствием того, что граждане видят, как тратятся бюджетные средства, и что власть слышит своих граждан.

7. Появляются территориальные сообщества граждан, проживающих рядом друг с другом и объединенных необходимостью решения общих проблем. Совместная реализация проектов инициативного бюджетирования приводит к формированию одного из важнейших элементов городской социальной ткани - соседским взаимоотношениям.

Тем не менее, сложившиеся в российских регионах подходы к финансированию и развитию отдельных форм гражданского участия и механизмов местных органов самоуправления можно рассматривать как фактор появления новых региональных программ инициативного бюджетирования. Смежные практики могут встраиваться как инструмент в программы инициативного бюджетирования, либо отдельные партисипаторные процедуры способны создать потенциал для трансформации смежных практик. В каждом из субъектов РФ можно искать и реализовывать собственные инновационные 
подходы, опираясь на местный опыт решения значимых для органов власти региона проблем.

Под софинансированием подразумевается дополнительное, наряду с выделением государственных субсидий из бюджета Российской Федерации, финансирование проектов, поддержанных гражданами. Финансирование из бюджета субъекта РФ составляет в среднем до 65\% стоимости проектов, из муниципальных бюджетов и со стороны граждан - оставшиеся 35\% в равных долях. Во многих регионах доля софинансирования гражданами не превышает 4-5\% от общей стоимости проектов (рисунок 1) [2].

Если непосредственными результатами реализации инициативного бюджетирования считать построенные или отремонтированные объекты инфраструктуры, то ряд сопутствующих реализации проектов инициативного бюджетирования результатов правильнее назвать экономическими эффектами. Среди них можно выделить следующие:

- Снижение стоимости проектов, повышение эффективности расходования бюджетных средств.

- Как показывает практика, стоимость проектов, реализованных посредством инициативного бюджетирования, существенно ниже проектов, реализованных без участия граждан. Поскольку для местных жителей возможность напрямую решить проблему своего сообщества предоставляется нечасто, они стараются полу- чить от этой возможности максимум и потратить средства экономно, но эффективно. В этом смысле жители берут на себя роль крайне заинтересованного и строгого общественного контролера.

- Повышение качества выполняемых работ в результате общественного контроля. Местные жители, проголосовавшие за тот или иной проект и, в особенности, внесшие софинансирование, пусть даже скромное, заинтересованы в том, чтобы проект был реализован качественно. Конкретные примеры из практики программы поддержки местных инициатив свидетельствуют, как граждане в рамках контроля подрядчиков самостоятельно измеряют ширину уложенного асфальта на дорогах и глубину вырытых траншей, требуя исправления выявленных нарушений.

- Повышение срока эксплуатации объектов.

- Выбирая тот или иной проект, жители не просто проявляют заинтересованность в его появлении, а включаются в его создание как активные участники. Отношение «общее - значит ничье» вытесняется заботливым хозяйским отношением к объектам инфраструктуры, минимизируется вандализм.

- Софинансирование проектов - важный ресурс развития общественных финансов. При этом важен не столько объем привлеченных средств, сколько само участие граждан в проектах рублем. Человек, внесший пусть небольшой, но персональный денежный вклад, ощущает

\section{СОФИНАНСИРОВАНИЕ} (предприятия, население, др.)

(добровольные пожертвования)

\section{РЕГИОНАЛЬНЫЙ БІОДЖЕТ}

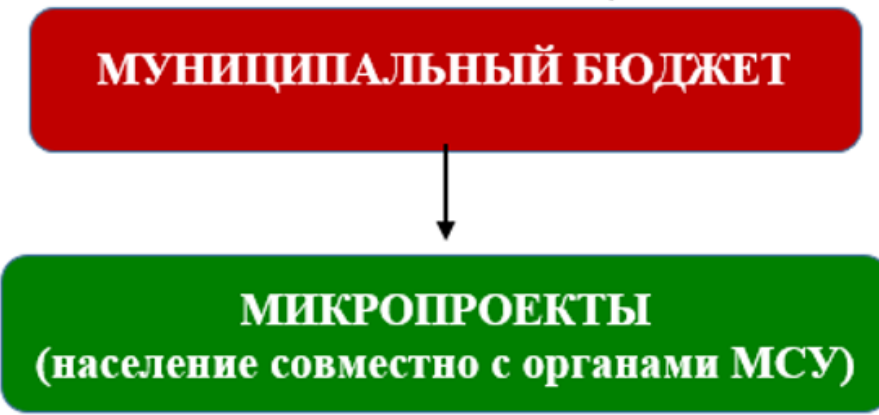

Puc. 1. Финансовые инструменты Программы поддержки местных инициатив (ППМИ) 
свою сопричастность к решаемым проблемам.

- Повышение уровня бюджетной грамотности населения.

- Не менее важным для граждан, наряду с получением основ финансовой грамотности, является бюджетная грамотность. Сопричастность бюджетным решениям - важнейшее условие формирования «ответственного гражданина». Снижение стоимости проектов, повышение эффективности расходования бюджетных средств [2].

\section{Библиографический список}

1. Белостоцкий А.А. Социально ориентированные расходы бюджетов на современном этапе // Финансовые и правовые аспекты социально ориентированного инвестирования: материалы Международной научно-практической конференции. Екатеринбург. 2017. 195 с.

2. Вагин В.В., Тимохина Е.А. 25 Вопросов об инициативном бюджетировании: учебное пособие. Москва. 2017. $46 \mathrm{c}$.

3. Бюджетный кодекс Российской Федерации. Статья 79. Бюджетные инвестиции в объекты государственной (муниципальной) собственности: официальный сайтсправочно - правовой системы «КонсультантПлюс»URL: http://www.consultant.ru/ (дата обращения: 17.11.2018).

4. Проект Закона Курской области «Об областном бюджете на 2019 год и на плановый период 2020 и 2021 годов». Официальная Курская область. Сервер органов власти Курской области: официальный сайт URL: http// www.rkursk.ru/ (дата обращения 25.11.2018).

5. Инвестиционный портал Курской области. Меры господдержки: официальный сайтURL: http//kurskoblinvest. ru/господдержка/меры-господдержки/(дата обращения 08.11.2018). 